... we are left wondering, as a profession, whether the Government are really

committed to providing a quality dental

service under the NHS for those who

require it in whatever region they live.

\title{
The President's New Year Message
}

My Presidential Year so far has witnessed highly significant developments for the future of dentistry, not the least of which is the Government report Options for Change which acknowledges that the current system for NHS dentistry is out of date. Backing this up, though from a different source, the Audit Commission Report agrees with this conclusion concerning the future of dentistry in the NHS in England and Wales.

This view is not confined to the professional press, as the realisation that we are on the verge of significant change, or perhaps the necessity for it, has reached the national press as well. Commenting about the Audit Commission in her article The Truth about Tooth Doctors in the Daily Express October 1st 2002, Dr. Rosemary stated that "a year after the Government's pledge to make dentistry available to all in the NHS, patients are still finding it impossible to find dental care without having to pay for it". The comments only serve to reinforce the view that there are many reports of the shortage of dentists, assistants and associates for general dental practice and even with the current strategy of Options for Change we are left wondering, as a profession, whether the Government are really committed to providing a quality dental service under the NHS for those who require it in whatever region they live. At least the $40 \%$ of all dental patients who currently receive private treatment are hopefully getting quality care.

Furthermore, in the dental education arena, there is some evidence that the undergraduate schools are under pressure to deliver the high quality of graduate education set out in the General Dental Council's curriculum document The First Five Years. This again is a symptom of the general lack of resource being committed to British universities as described in The Economist November 162002 - The Ruin of Britain's Universities. This critical state of affairs in dental education requires to be addressed urgently.

On a more optimistic note, the Medical Research Council's recent report brought water fluoridation a step closer by the Government responding with a request to the Chief Dental Officer and the Chief Medical Officer in England to get together to co-ordinate and drive forward the initiative. Perhaps the time has come for us to witness Government commitment in this muchneglected area, instead of the usual encouragement without the required legislative activity to ensure fluoridation becomes a reality.

In the midst of all this activity around us, the BDA will play an increasingly important role in ensuring the profession is involved and heard. The BDA is determined to reinforce its commitment to both the NHS and private sector by the formation of the new BDA General Dental Practice Committee, which will help to reshape dental care in the 21st century in an increasingly mixed health economy. The Association also took advantage of the Office of Fair Trading enquiry to carry out a full investigation and then submit its evidence to promote to the public and the profession the reality and benefits of variations in private funding in dentistry.

As a token of its confidence in the BDA, the profession has voted with its feet and with all credit to the recruitment initiative, has polled the highest ever membership of over 21,000 members, representing 60\% of all registered dentists - it is determined to get the other $40 \%$ !

To further enhance its support to members and the profession, the BDA has already commenced a considerable programme of refurbishment as evidence by the scaffolding at headquarters, to develop a more user-friendly, streamlined and efficient facility that the profession can be proud of. A sizeable sponsorship programme is in progress to assist in funding the next phase of the project which would include providing a new attractive 'front window' for all visitors, as well as improved facilities for members 'dropping in'. Be sure to visit No. 64 when you are next in London to inspect the plans for the new look premises and take advantage of the benefits of membership for yourself.

lan C. Benington BDA President 